\title{
Tlx3 Controls Cholinergic Transmitter and Peptide Phenotypes in a Subset of Prenatal Sympathetic Neurons
}

\author{
Tianwen Huang, ${ }^{\star}$ Jia Hu, ${ }^{*}$ Bing Wang, Yanzhen Nie, Junlan Geng, and Leping Cheng \\ Institute of Neuroscience and State Key Laboratory of Neuroscience, Shanghai Institutes for Biological Sciences, Chinese Academy of Sciences, Shanghai \\ 200031, China
}

\begin{abstract}
The embryonic sympathetic nervous system consists of predominantly noradrenergic neurons and a very small population of cholinergic neurons. Postnatal development further allows target-dependent switch of a subset of noradrenergic neurons into cholinergic phenotype. How embryonic cholinergic neurons are specified at the prenatal stages remains largely unknown. In this study, we found that the expression of transcription factor Tlx 3 was progressively restricted to a small population of embryonic sympathetic neurons in mice. Immunostaining for vesicular acetylcholine transporter (VAChT) showed that Tlx3 was highly expressed in cholinergic neurons at the late embryonic stage E18.5. Deletion of Tlx3 resulted in the loss of Vacht expression at E18.5 but not E12.5. By contrast, Tlx 3 was required for expression of the cholinergic peptide vasoactive intestinal polypeptide (VIP), and somatostatin (SOM) at both E12.5 and E18.5. Furthermore, we found that, at E18.5 these putative cholinergic neurons expressed glial cell line-derived neurotrophic factor family coreceptor Ret but not tyrosine hydroxylase $\left(\mathrm{Ret}^{+} / \mathrm{TH}^{-}\right)$. Deletion of $T l x 3$ also resulted in disappearance of high-level Ret expression. Last, unlike Tlx3, Ret was required for the expression of VIP and SOM at E18.5 but not E12.5. Together, these results indicate that transcription factor $T l x 3$ is required for the acquisition of cholinergic phenotype at the late embryonic stage as well as the expression and maintenance of cholinergic peptides VIP and SOM throughout prenatal development of mouse sympathetic neurons.
\end{abstract}

\section{Introduction}

The sympathetic nervous system is a major component of the autonomic nervous system that maintains the homeostasis of the internal environment during diverse physiological conditions (Cannon, 1939; Janig and McLachlan, 1992). Mature mammalian and avian sympathetic ganglia are composed of two types of neurons. The vast majority of sympathetic neurons are noradrenergic and express molecular markers, such as tyrosine hydroxylase (TH) and dopamine $\beta$-hydroxylase (DBH). By contrast, a small subset of sympathetic neurons use acetylcholine as transmitter and can be discriminated by the expression of choline acetyltransferase (ChAT) and vesicular acetylcholine transporter (VAChT) (Elfvin et al., 1993; Ernsberger and Rohrer, 1999). Diversity of mature sympathetic neurons is also indicated by the restricted expression of peptides in distinct subpopulations (Elfvin et al., 1993; Gibbins, 1995). How the diversity of the sym-

Received Jan. 15, 2013; revised May 7, 2013; accepted May 15, 2013.

Author contributions: L.C. and T.H. designed research; T.H., J.H., B.W., Y.N., and J.G. performed research; L.C., T.H., and J.H. analyzed data; L.C. and T.H. wrote the paper.

This work was supported by the "Strategic Priority Research Program" of the Chinese Academy of Sciences (Grant No. XDA01020306), and the 973 Program from The Ministry of Science and Technology of China (2011 CBA00400). We thank Dr. M.-m. Poo for critical comments on this paper, and Drs S. Shirasawa and S. Korsmeyer for T/x3-null mice.

*T.H. and J.H. contributed equally to this work.

T. Huang's present address: Dana-Farber Cancer Institute and Department of Neurobiology, Harvard Medical School, Boston, MA 02115.

Correspondence should be addressed to Dr Leping Cheng, Institute of Neuroscience and State Key Laboratory of Neuroscience, Shanghai Institutes for Biological Sciences, Chinese Academy of Science, 320 Yue Yang Road,Shanghai 200031, China. E-mail: Ipcheng@ion.ac.cn.

DOI:10.1523/JNEUROSCI.0192-13.2013

Copyright $\odot 2013$ the authors $\quad 0270-6474 / 13 / 3310667-09 \$ 15.00 / 0$ pathetic neurons is generated during development is a major question for studying neural development (Le Douarin and Kalcheim, 1999; Howard, 2005; Huber, 2006).

Substantial progress has been made in understanding the extrinsic signals and intrinsic transcription factors that control the acquisition of noradrenergic phenotype in sympathetic neurons (Apostolova and Dechant, 2009; Cane and Anderson, 2009; Rohrer, 2011). Transcription factors Phox $2 b$ and Hand2 are required to maintain the noradrenergic traits, whereas Gata3 is required for the survival of differentiated noradrenergic neurons (Schmidt et al., 2009; Coppola et al., 2010; Tsarovina et al., 2010). For cholinergic differentiation in sympathetic neurons, there are two modes of how sympathetic neurons acquire their cholinergic phenotype (Ernsberger and Rohrer, 1999; Francis and Landis, 1999; Ernsberger, 2001). In the classic postnatal targetdependent cholinergic differentiation, the sudomotor neurons and the neurons that innervate the periosteum initially express noradrenergic phenotype, but acquire the cholinergic phenotype while losing functional adrenergic properties after contacting the target tissue (Landis, 1990; Asmus et al., 2000). The switch from noradrenergic to cholinergic phenotype is initiated by signals released from the target (e.g., sweat glands) (Apostolova and Dechant, 2009; Cane and Anderson, 2009). The glycoprotein (gp)130 receptor that is expressed in sympathetic neurons is indispensable for the target-dependent acquisition of cholinergic phenotype (Stanke et al., 2006). Prenatal expression of cholinergic properties has also been found in a very small population of developing sympathetic neurons of rodents and chick (Ernsberger et al., 1997; Schäfer et al., 1997; Schütz et al., 1998). Further studies revealed that transcription factor Phox $2 b$ and Ret, the 

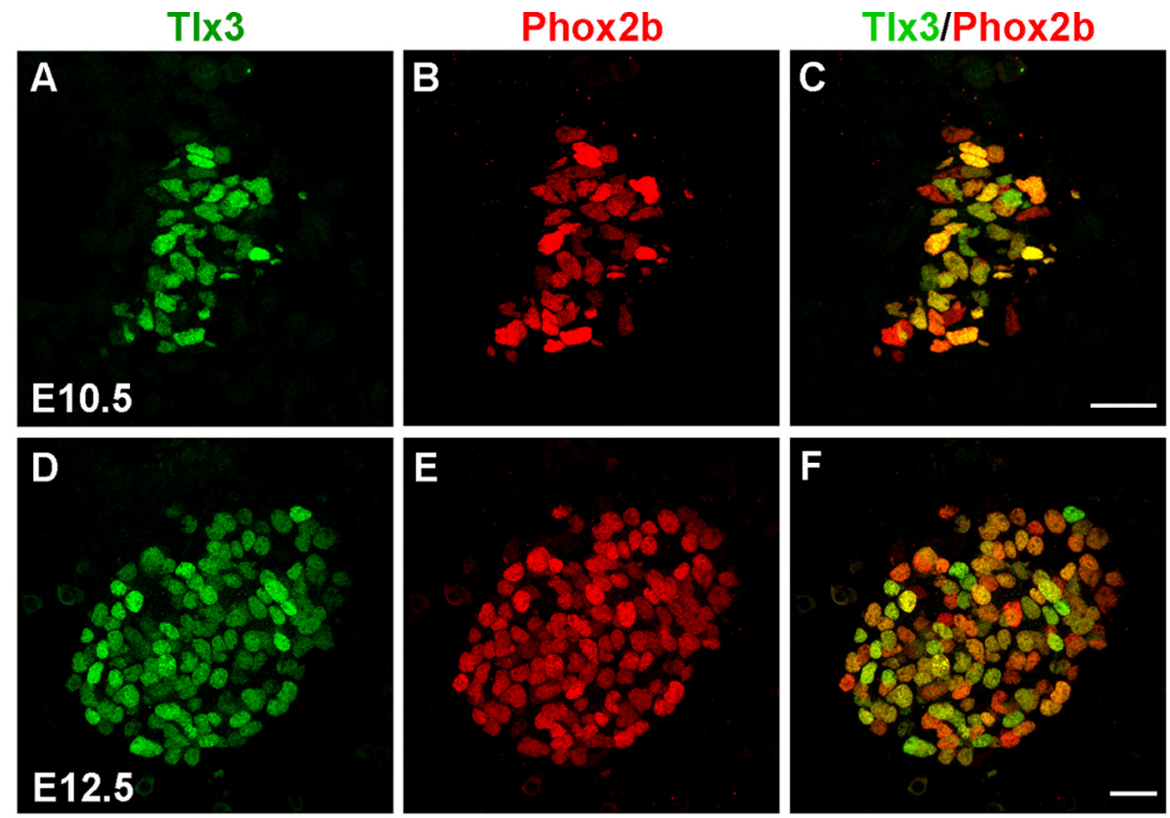

E14.5
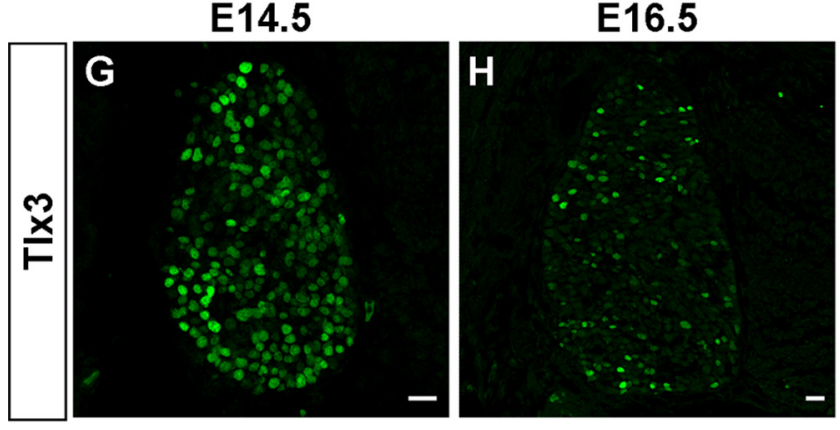

E18.5

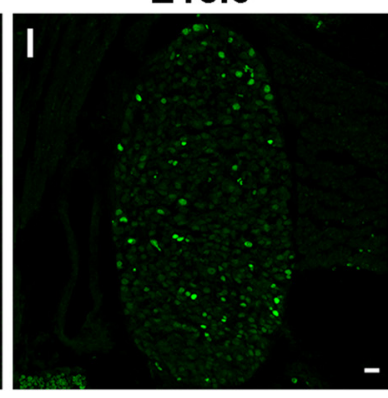

\section{$\mathbf{J}$}

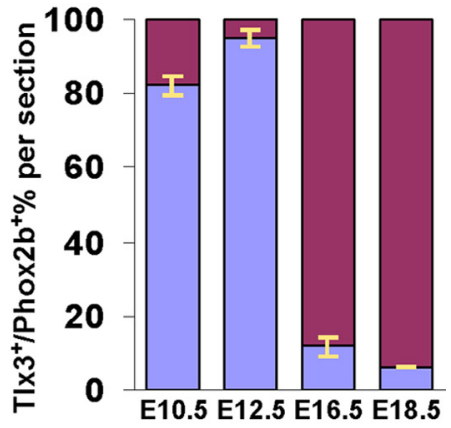

\section{TIx3/VAChT/TH}
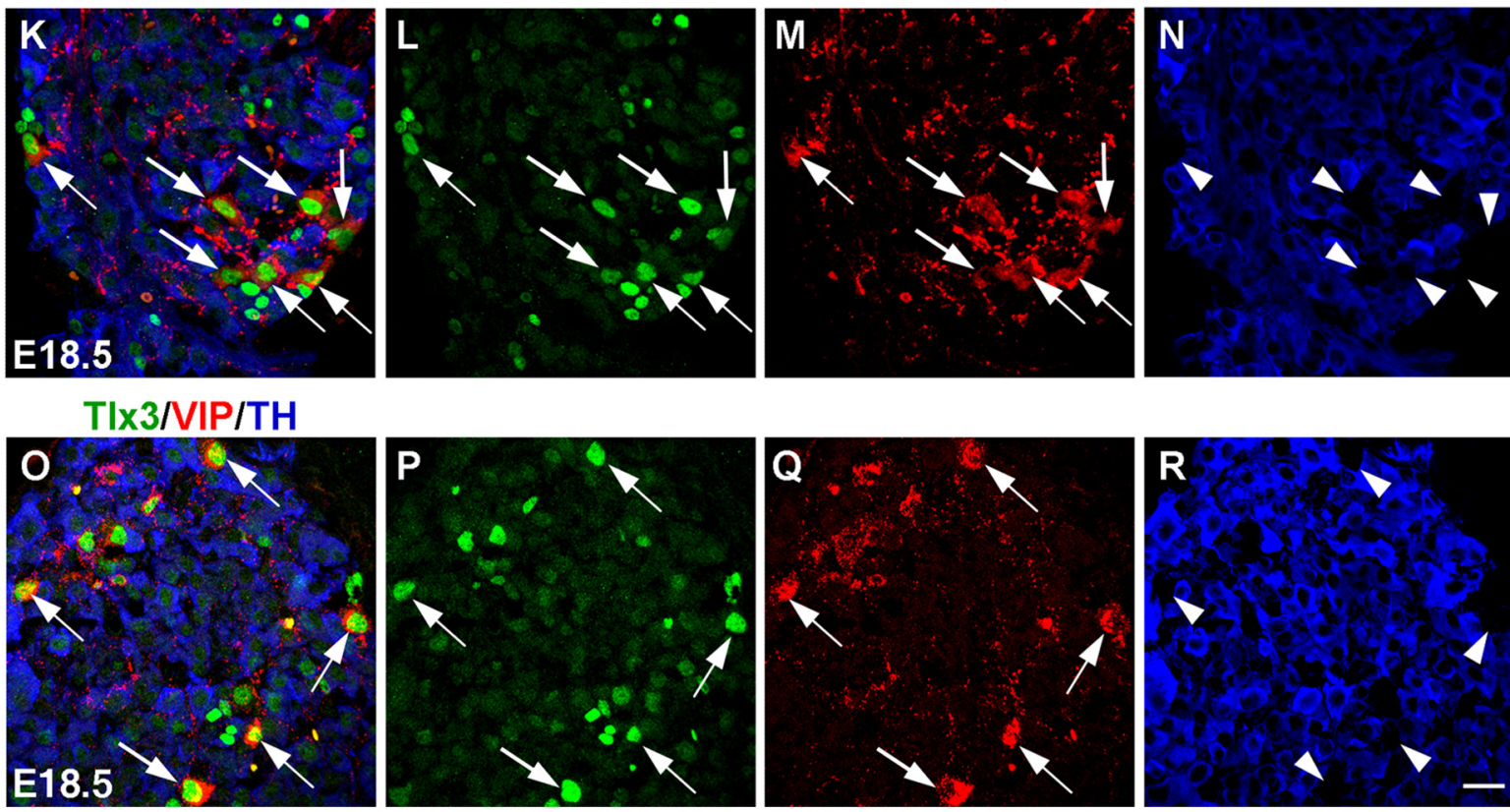

Figure 1. Expression of TIX3 in the embryonic sympathetic ganglia of mouse. $A-I$, Immunostaining of T|x3 was performed on transverse sections of the primary sympathetic chain from wild-type mice at E10.5 (A), and stellate ganglia atE12.5 (D), E14.5 (G), E16.5 (H), and E18.5 (I). Double staining of Tlx3 and Phox2b was performed atE10.5 $(\boldsymbol{A}-\boldsymbol{C})$ and E12.5 (D-F).J, The number of Tlx ${ }^{+}$cells was determined in sympathetic ganglia at E10.5, E12.5, E16.5, and E18.5 relative to the total number of Phox2b ${ }^{+}$cells. $\boldsymbol{K}-\boldsymbol{R}$, Triple immunostaining of TIX3, TH, and VAChT $(\boldsymbol{K}-\boldsymbol{N})$ or VIP $(\boldsymbol{O}-\boldsymbol{R})$ was performed on sections of stellate ganglia at E18.5. Arrows $(\boldsymbol{K}-\mathbf{M}, \mathbf{O}-\mathbf{Q})$ and arrowheads $(\boldsymbol{N}, \boldsymbol{R})$ showed the majority of $\mathrm{ACChT}^{+} / \mathrm{TH}^{-}$and VIP ${ }^{+} / \mathrm{TH}^{-}$cells coexpressed Tlx3. Scale bars: $\mathbf{A}-\boldsymbol{F}, \boldsymbol{K}-\boldsymbol{R}, 10 \mu \mathrm{m} ; \mathbf{G}-\mathbf{I}, 20 \mu \mathrm{m}$. 


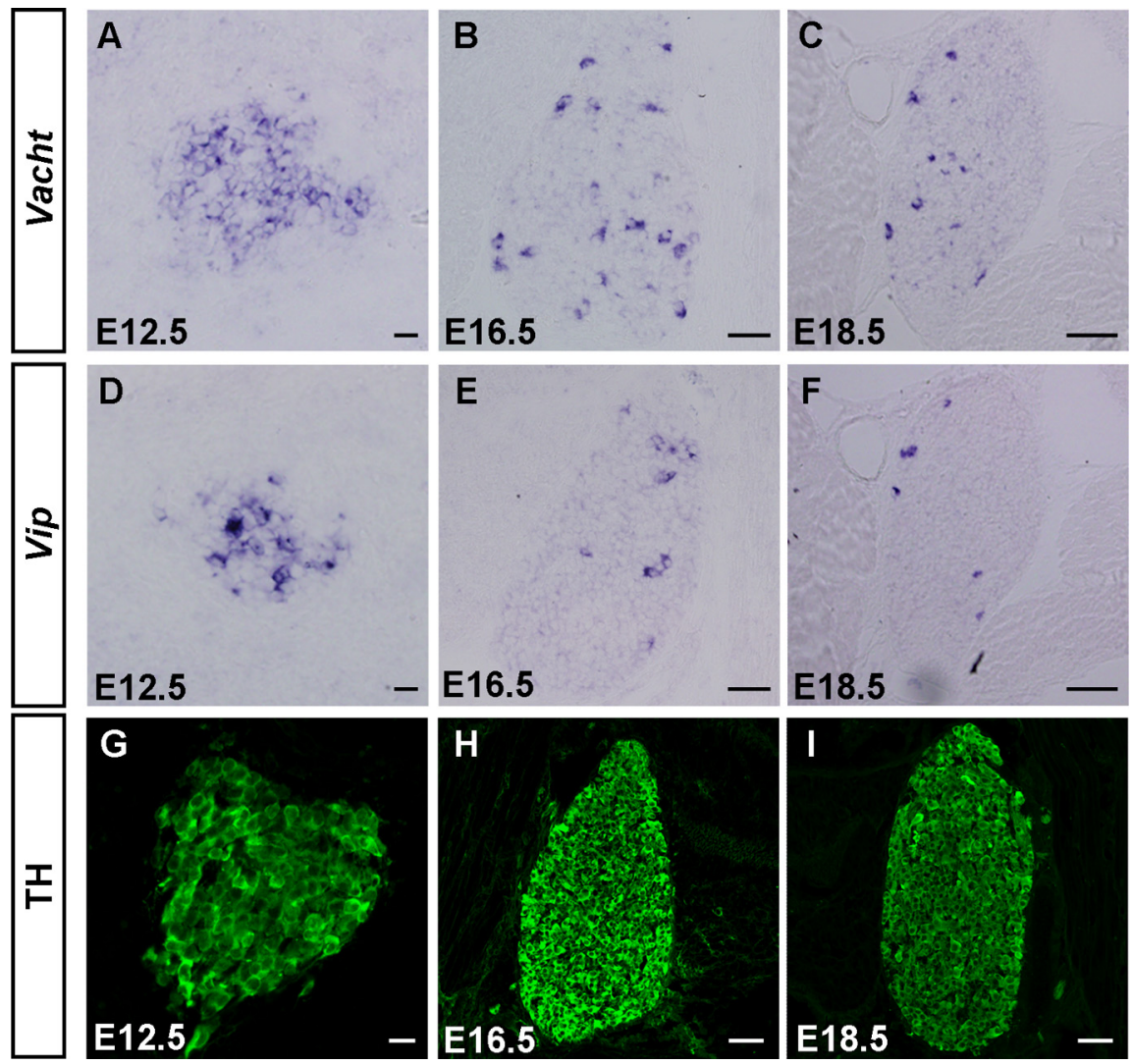

Figure 2. Different expression patterns of cholinergic and noradrenergic neuronal markers during embryonic sympathetic development. $\boldsymbol{A}-\boldsymbol{F}$, In situ hybridization was performed on sections of stellate ganglia from wild-type mice at E12.5, E16.5, and E18.5 with Vacht $(\boldsymbol{A}-\boldsymbol{C})$, and Vip $(\boldsymbol{D}-\boldsymbol{F})$ as the probes. Note a progressively restricted expression pattern of Vacht. G-I, Immunostaining of TH was performed on sections of stellate ganglia from wild-type mice at E12.5, E16.5, and E18.5. The persistently widespread expression of TH was observed during embryonic sympathetic development. Scale bars: $\boldsymbol{A}, \boldsymbol{D}, \boldsymbol{G}, 20 \mu \mathrm{m} ; \boldsymbol{B}, \boldsymbol{C}, \boldsymbol{E}, \boldsymbol{F}, \boldsymbol{H}$, I, $50 \mu \mathrm{m}$.

glial cell line-derived neurotrophic factor (GDNF) family ligands (GFLs) coreceptor, are required for this embryonic cholinergic differentiation (Burau et al., 2004; Huber and Ernsberger, 2006). However, the molecular mechanism that controls the development of embryonic cholinergic neurons remains largely unknown.

The homeodomain transcription factor Tlx3 and Tlx1 determine glutamatergic over GABAergic cell fates and the expression of corresponding peptides and transmitter receptors in the dorsal spinal cord (Cheng et al., 2004, 2005; Xu et al., 2008; Guo et al., 2012; Hu et al., 2012). Here, we report that Tlx3 is enriched in the cholinergic subset of sympathetic neurons at the late embryonic stage and is required for their proper phenotypic development.

\section{Materials and Methods}

Mouse strains. The generation of Tlx 3 mutant mice was described previously (Shirasawa et al., 2000). Ret mutant mice were kindly donated by Dr. Frank Costantini (Columbia University Medical Center, New York, NY) and obtained from The Jackson Laboratory (Schuchardt et al., 1994). In all timed mating using both male and female mice, the morning that vaginal plugs were observed was designated as E0.5. Genotyping for Tlx3 mutant mice was done as described previously (Qian et al., 2002). Wild-type Ret allele was identified with the information provided by The Jackson Laboratory and the mutant Ret allele was amplified with the following primers that produce a 651 bp product: 5'-AGTCTCCAAGGCAATTTCAACG-3' and 5'-GCCCAATAGCAGCCAGTCC-3'. All animal procedures are contained in protocols reviewed and approved by the Animal Care Committee at the Institute of Neuroscience, Shanghai Institutes for Biological Sciences, Chinese Academy of Sciences.

In situ hybridization and immunostaining. In situ hybridization experiments were performed as described previously (Huang et al., 2010). Riboprobe for mouse Vacht (NM_021712, $1.14 \mathrm{~Kb}$ ) and Vip (NM_011702, $1.04 \mathrm{~kb}$ ) were used. Sst in situ probe was described previously (Huang et al., 2008).

Immunostaining was performed as described previously (Huang et al., 2010). The following antibodies were used: rabbit antiTlx3 antibody (1:400) (Huang et al., 2010), guinea pig anti-Tlx3 (1:1000, kind gift from C. Birchmeier, Max Delbrück Center for Molecular Medicine, Berlin, Germany), goat antiVAChT (1:50, Santa Cruz Biotechnology), rabbit anti-VAChT (1:500, SYSY), goat antiVIP (1:200, Santa Cruz Biotechnology), goat anti-SOM (D-20; 1:300, Santa Cruz Biotechnology), mouse anti-TH (1:500, SigmaAldrich), rabbit anti-TH (1:500, Pel-Freez), goat anti-Ret (1:25, R\&D Systems), goat antiPhox2b (1:50, Santa Cruz Biotechnology), rabbit anti-SOM (H-106) (1:50, Santa Cruz Biotechnology), mouse anti-CGRP (1:500, Sigma-Aldrich).

Cell counting. Stellate ganglion from three pairs of control and mutant embryos $(10 \mu \mathrm{m})$ were analyzed with various molecular markers. Immunoreactive cells with signal highly above the background were counted and the values were presented as mean \pm SEM. The differences in values were considered to be significant at $p<0.05$ by Student's $t$ test.

\section{Results}

\section{Expression of Tlx 3 in sympathetic} cholinergic neurons

To study the expression of transcription factor Tlx 3 in the developing sympathetic neurons, we performed immunostaining experiments on sympathetic ganglia of mouse embryos from E9.5 to E18.5. The first Tlx $3^{+}$cells were detectable at E10.5 and found to coexpress Phox $2 \mathrm{~b}$, which is known to be expressed in early sympathetic progenitors (Pattyn et al., 1997, 1999), indicating that Tlx3 was highly expressed in developing sympathetic ganglia (Fig. 1A-F). Approximately $82 \%$ and $95 \%$ Phox $2 b^{+}$cells expressed Tlx3 at E10.5 and E12.5, respectively (Fig. $1 J$ ). Over the next few days, Tlx3 expression was progressively restricted to a small population of sympathetic neurons (Fig. 1G-I). At E16.5 and E18.5, the percentage of Phox $2 \mathrm{~b}^{+}$neurons that expressed Tlx3 reduced to $17 \%$ and $6 \%$, respectively (Fig. $1 J$ ). This progressive restriction of $\mathrm{Tlx} 3$ expression in sympathetic neurons was reminiscent of the restrictive expression pattern of cholinergic marker genes in rodent and chick sympathetic neurons at prenatal stages (Ernsberger et al., 1997; Schütz et al., 1998; Burau et al., 2004; Huber and Ernsberger, 2006) (Fig. 2). Furthermore, gene expression studies performed in chicken sympathetic ganglia have shown that $T l \times 3$ is among the genes upregulated by factors that induce cholinergic neuronal differentiation in vitro (Apostolova et al., 2007). To determine whether Tlx3 is associated with cholinergic neuronal differentiation in developing sympathetic ganglia, we performed triple staining of the stellate ganglia at embryonic stages, where a small population of cholinergic neu- 
rons has been observed at the prenatal stages (Schäfer et al., 1997; Schütz et al., 1998). VAChT and ChAT are well known molecular markers for cholinergic neurons (Ernsberger and Rohrer, 1999). In situ hybridization studies have shown that the expression level of Vacht is higher than that of Chat in sympathetic neurons (Burau et al., 2004). Thus, we focused on VAChT expression in this study. Immunostaining results showed that VAChT and $\mathrm{TH}$ were coexpressed in many neurons at E12.5, but in largely separated populations by E18.5 (Fig. $1 K-N$ and data not shown). Meanwhile, the majority of $\mathrm{VAChT}^{+}$neurons (82\%) expressed Tlx3 at E18.5 (Fig. $1 K-N$ ). Vasoactive intestinal polypeptide (VIP) is known to be expressed in cholinergic neurons of stellate ganglia in newborn mice (Stanke et al., 2000). Indeed, our immunostaining results showed that the majority of $\mathrm{VIP}^{+}$ neurons (80\%) expressed Tlx3 (Fig. 1O$R)$. Thus, most of the cholinergic neurons express Tlx3 during late embryonic stages.

It has been reported that cholinergic sympathetic neurons in adult stellate ganglia that innervate sweat glands acquire cholinergic properties largely between $\mathrm{P} 4$ and P21 through target-dependent gp 130 signaling (Guidry and Landis, 1998; Ernsberger and Rohrer, 1999; Francis and Landis, 1999; Stanke et al., 2006). Those sudomotor neurons are characterized by the expression of calcitonin gene-related peptide (CGRP) (Landis and Fredieu, 1986; Anderson et al., 2006). To study whether Tlx3 was expressed in the secondwave of cholinergic neurons, we performed immunostaining experiments on postnatal stellate ganglia. The results showed that Tlx3 was clearly expressed in a subset of sympathetic neurons at P14 and P60 (Fig. $3 A, B$ ). Furthermore, double staining results showed that $\mathrm{Tlx} 3^{+}$ neurons expressed CGRP at P14 and P30 (Fig. $3 C-H$ ). Tlx3 also was nicely colocalized with VIP in sympathetic neurons: most $\mathrm{Tlx}^{+}$neurons (87\%) expressed VIP and $\sim 42 \%$ VIP $^{+}$neurons expressed Tlx3 at P30 (Fig. 3I-N). Meanwhile, double staining results revealed that almost all of the VIP ${ }^{+}$neurons coexpressed VAChT at $\mathrm{P} 14$ and $\mathrm{P} 60$ (data not shown). A recent study also showed that Tlx3 was expressed in cholinergic neurons at P60 (Furlan et al., 2013). Together, Tlx3 was expressed in the postnatal emergence of cholinergic neurons as well.

\section{Tlx 3 controls development of cholinergic neurons}

To determine whether Tlx3 was required for the development of cholinergic neurons in stellate ganglia, we examined the expres$A, B, 50 \mu \mathrm{m}$
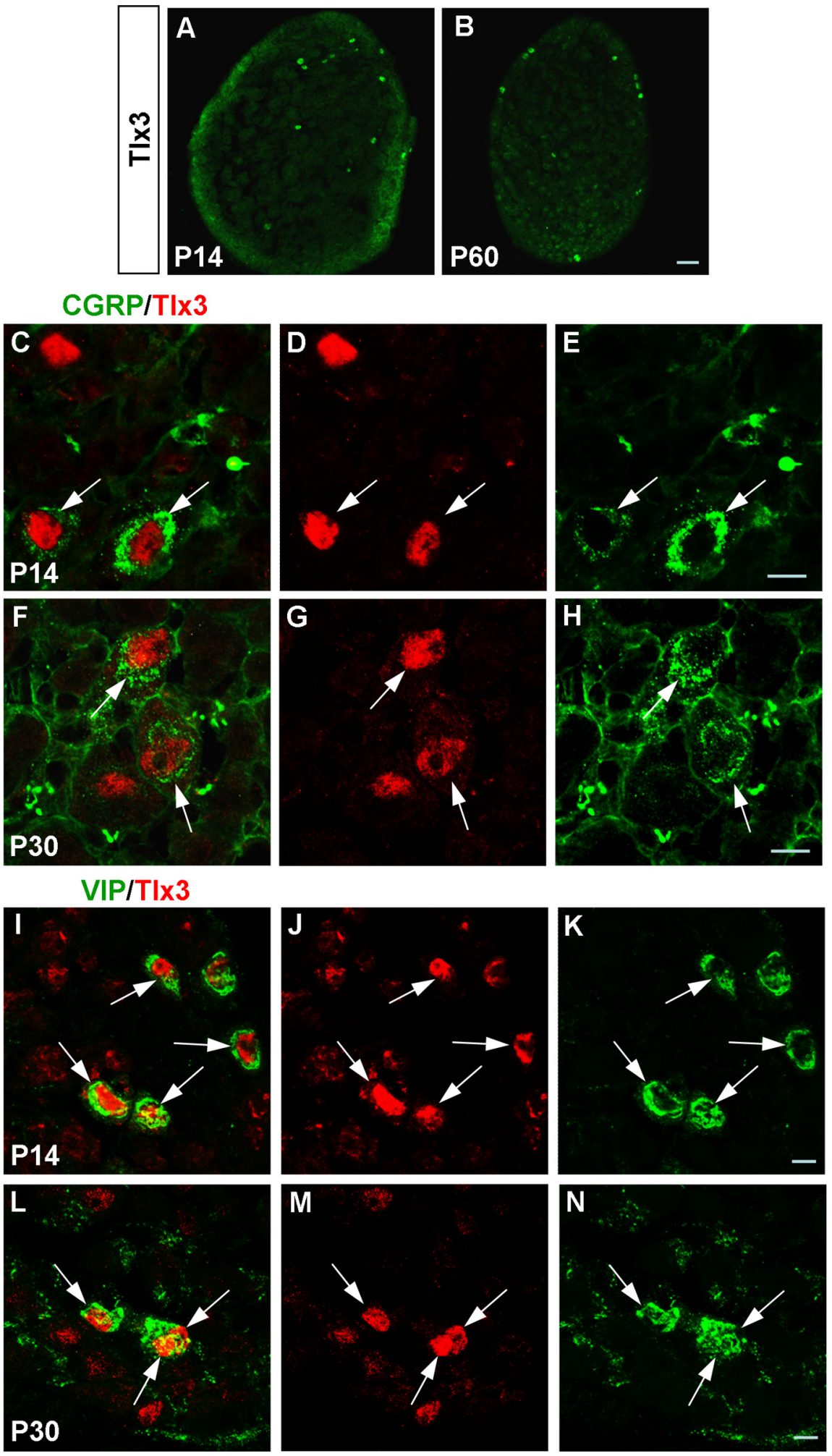

Figure 3. Expression of TIx3 in the postnatal sympathetic ganglia of mouse. $A, B$, Immunostaining of Tlx3 was performed on sections of stellate ganglia from wild-type mice at P14 (A) and P60 (B).C $-\boldsymbol{H}$, Double immunostaining of Tlx3 and CGRP was performed on sections of stellate ganglia from wild-type mice at P14 (C-E) and P30 (F-H). I-N, Double immunostaining of TIx3 and VIP was performed on sections of stellate ganglia from wild-type mice at P14 $(\boldsymbol{I}-\boldsymbol{K})$ and P30 $(\boldsymbol{L}-\boldsymbol{N})$. Scale bars: $\mathbf{C}-\boldsymbol{N}, 10 \mu \mathrm{m}$;

sion of Vacht and Vip in control (wild-type or $T l \times 3^{+/-}$) and Tlx3 deletion $\left(T l \times 3^{-1-}\right)$ mice by in situ hybridization. The results showed that the early expression of Vacht at E12.5 was similar between control and $T l \times 3^{-1-}$ mice, whereas the expression of 
Vacht expression at E18.5 was abolished in $T l \times 3^{-1-}$ mice but not in control mice (Fig. $4 A-D$ ). In contrast, the expression of Vip was eliminated in Tlx $3^{-l-}$ mice at both E12.5 and E18.5 (Fig. $4 E-H)$. To determine whether Tlx3 controlled the development of noradrenergic neurons in the stellate ganglion, we examined the expression of $\mathrm{TH}$ and transcription factors that are required for the development of noradrenergic neurons, including Phox2b, Hand2, Gata3, and Insm1, in the Tlx $3^{-1-}$ mice at E12.5 and E18.5. The results showed that the expression of these molecular markers were largely unaffected when $T l \times 3$ was fully ablated (Figs. 4I-L, 5).

Some VIP-expressing neurons in the stellate ganglia of rat are also known to express the neuropeptide somatostatin (SOM) (Masliukov and Timmermans, 2004). To determine whether SOM or the gene Sst that encodes SOM was expressed in embryonic cholinergic neurons, we performed in situ hybridization and immunostaining experiments. The results showed that Sst was consistently expressed in a small portion of neurons in embryonic stellate ganglia (Fig. $6 A-D)$. Furthermore, most of the VAChT-expressing cholinergic neurons $(83 \%)$ expressed SOM and $\sim 64 \%$ of $\mathrm{VIP}^{+}$neurons expressed SOM at E18.5 (Fig. $6 E-L$ ). We also found that most $\mathrm{SOM}^{+}$ neurons (89\%) expressed Tlx3 at E18.5 (Fig. 6M-P). Finally, we examined whether $T l \times 3$ was required for the expression of SOM or Sst and found that the expression of SOM or Sst at both E12.5 and E18.5 was eliminated in $T l \times 3^{-1-}$ mice (Fig. $6 Q-T$ ). Together, these results showed that $T l \times 3$ is required for the embryonic development of cholinergic neurons in the stellate ganglion by specifying the expression of Vacht, Vip, and SOM. The neonatal lethality of Tlx3 mutant mice (Shirasawa et al., 2000) prevented us from studying whether $T l \times 3$ controls the development of the second-wave of cholinergic neurons at the postnatal stages.

\section{Expression of Ret in developing stellate ganglia of $T l x 3$ deletion mice}

Ret has been shown to regulate cholinergic properties in embryonic mouse sympathetic neurons (Burau et al., 2004). To determine the relationship between Tlx3 and Ret in cholinergic development, we first examined whether they are colocalized in the same cells. Immunostaining results showed that the majority of Ret ${ }^{+} / \mathrm{TH}^{-}$neurons $(87 \%)$ expressed Tlx 3 in wild-type mice (Fig. $7 A-D)$. Triple staining results further showed that most $\mathrm{Ret}^{+} / \mathrm{TH}^{-}$neurons (92\%) were indeed cholinergic neurons (Fig. $7 E-H$ ). Then we examined whether $T l \times 3$ was required for the expression of Ret in the putative cholinergic $\left(\mathrm{Ret}^{+} / \mathrm{TH}^{-}\right)$neurons by analyzing the $T l \times 3^{-1-}$ mice. Interestingly, the small number of putative cholinergic $\left(\mathrm{Ret}^{+} / \mathrm{TH}^{-}\right)$ neurons disappeared, whereas the majority of $\operatorname{Ret}^{+} / \mathrm{TH}^{+}$neurons were unaffected in $T l x 3^{-1-}$ mice at E18.5 (Fig. $7 I-L$, arrows). It was unclear whether the disappearance of cholinergic $\left(\mathrm{Ret}^{+} / \mathrm{TH}^{-}\right)$neurons in $T l \times 3^{-1-}$ mice was due to the downregulation of high-level expression of Ret in these neurons or cell death. The relatively constant number of Ret $^{+}$neurons in control and $T l \times 3$ deletion mice (control: $70 \pm 2$ vs $T l \times 3^{-1-}: 71.3 \pm 1.4$ cells/section) suggested that Ret $^{+} / \mathrm{TH}^{-}$neurons may have changed their fate from cholinergic to noradrenergic phenotype $\left(\operatorname{Ret}^{+} / \mathrm{TH}^{+}\right)$by gaining the expression of $\mathrm{TH}$ (Fig. $7 \mathrm{I}, \mathrm{K}$ ). Because the number of $\mathrm{Ret}^{+} / \mathrm{TH}^{-}$neurons was small ( $\sim 8$ neurons/section), it remains to be determined whether cell type switch had indeed occurred. Nevertheless, the above results indicated that $T l \times 3$ is required to maintain the high-level expression of Ret in embryonic cholinergic neurons in the sympathetic ganglion.
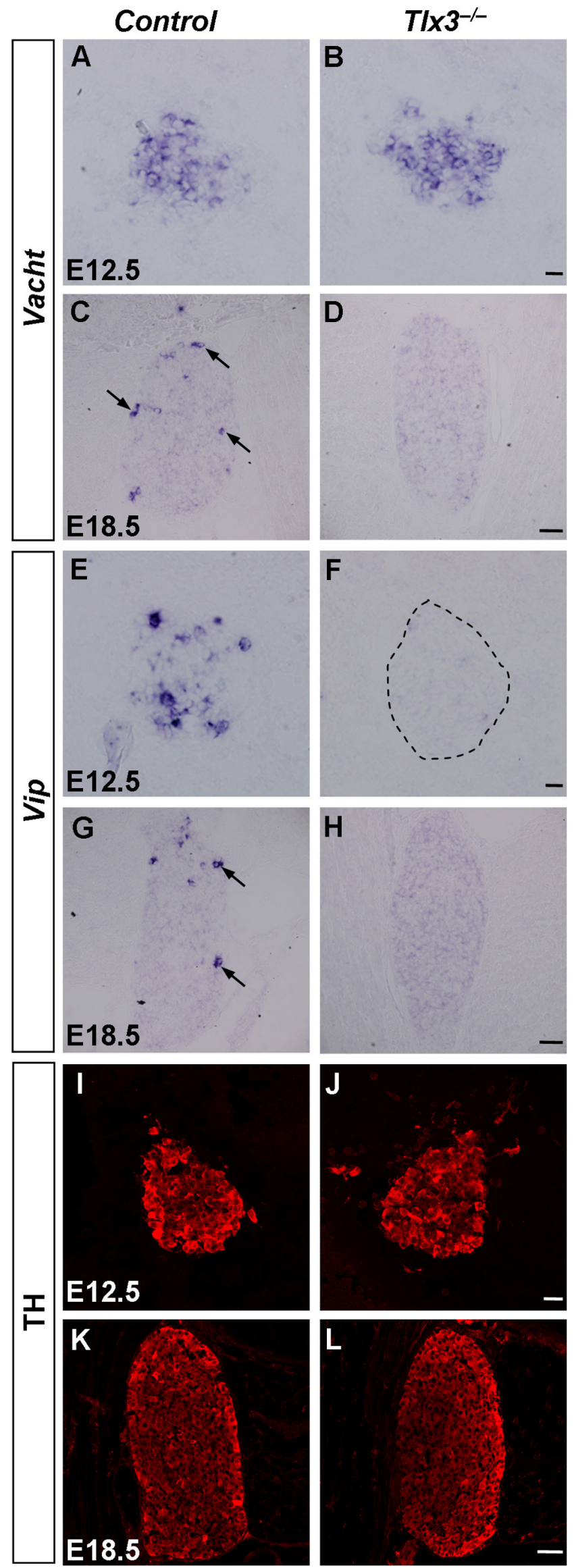

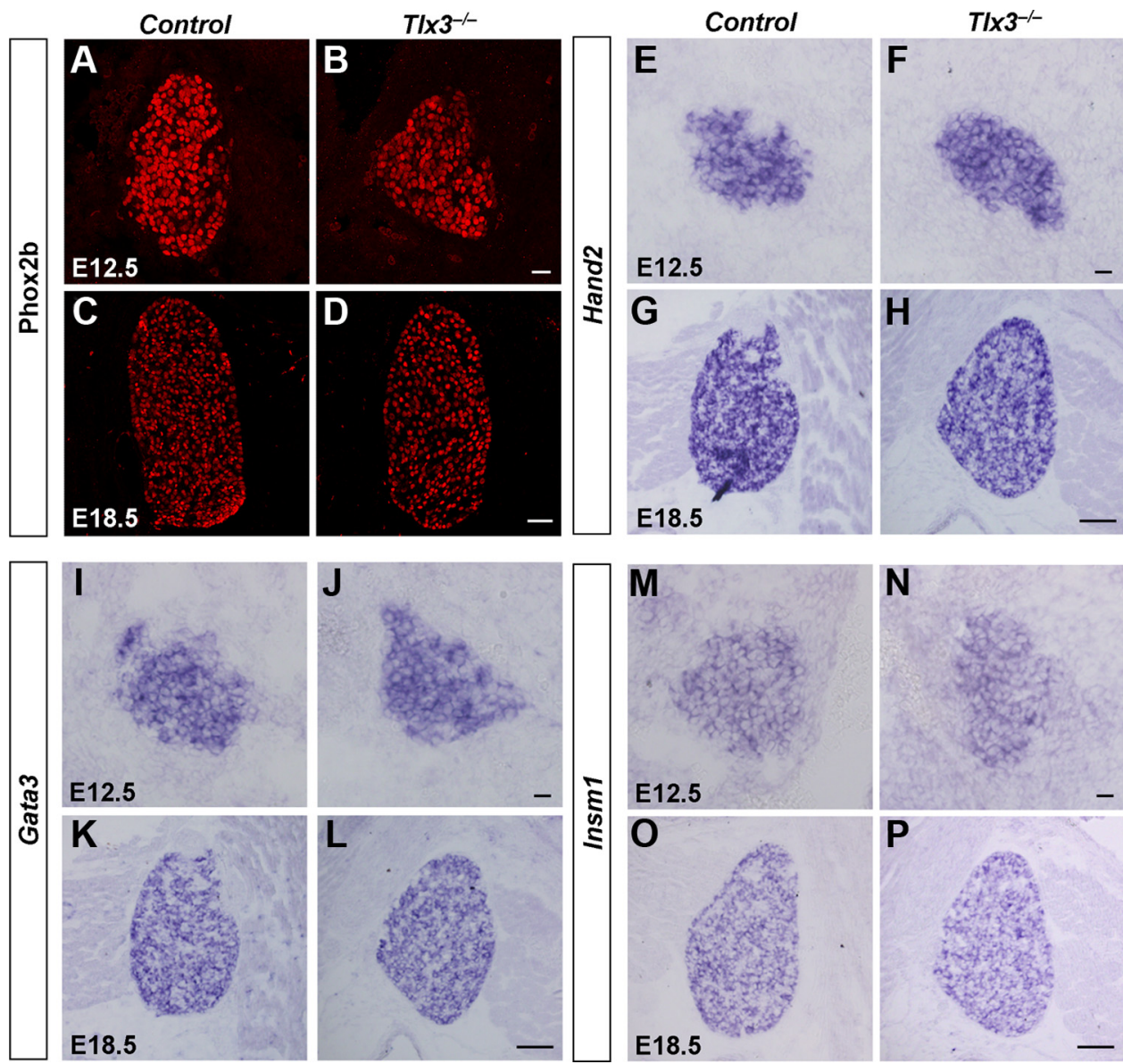

Figure 5. Expression of some molecular markers in $T / \times 3^{-1-}$ mice. $A-D$, Immunostaining of Phox $2 b$ was performed on sections of stellate ganglia from control and $T / \times 3^{-/-}$mice at $E 12.5$ and E18.5.E-P, In situ hybridization was performed on sections of stellate ganglia from control and $T / x 3^{-I-}$ mice at E12.5 and E18.5 with Hand2 (E-H), Gata3 (I-L), and Insm $1(\boldsymbol{M}-\boldsymbol{P})$ as the probes. No apparent differences were seen in the control and $T / \times 3^{-1-}$ mice. Scale bars: $A, B, E, F, I, J, M, N, 20 \mu \mathrm{m} ; C, D, G, H, K, L, \mathbf{O}, \mathbf{P}, 50 \mu \mathrm{m}$.

\section{Ret controls peptide genes Sst and Vip in developing stellate ganglia \\ To determine whether Ret is required for the expression of pep- tides Vip and Sst, we performed in situ hybridization experi- ments. The results showed that the expression of Vip and Sst remained present in $\operatorname{Ret}^{-1-}$ mice at E12.5 whereas their expres- sion was eliminated by E18.5 (Fig. $7 M-T$ ). This indicated that Ret coordinately controlled the expression of transmitter and peptide phenotypes in stellate ganglia at the late embryonic stage. This is distinct from the action of $T l x 3$, which controls the expression of these peptides since E12.5.}

\section{Discussion}

In this study, we found that high-level expression of transcription factor Tlx3 was widely present in early embryonic stellate ganglionic neurons and became progressively enriched in cholinergic neurons at late embryonic and postnatal stages. Analysis of the

Figure 4. Loss of cholinergic properties in stellate ganglia of $T / x 3^{-/-}$mice. $\boldsymbol{A}-\boldsymbol{H}$, In situ hybridization was performed on sections of stellate ganglia from control and $T / \times 3^{-1-}$ mice at E12.5 and E18.5 with Vacht $(\boldsymbol{A}-\boldsymbol{D})$, and Vip $(\boldsymbol{E}-\boldsymbol{H})$ as the probes. The Vacht and Vip signals were absent in $T / \times 3^{-1-}$ mice at E18.5. Note that the expression of Vacht was comparable in $T / x 3^{-1-}$ versus control mice, whereas the expression of Vip was abolished in $T / \times 3^{-1-}$ mice early at E12.5. I-L, Immunostaining of TH was performed on sections of stellate ganglia from control and $T / \times 3^{-1-}$ mice at E12.5 and E18.5. No apparent difference was observed between $T / \times 3$ mutant and control mice. Scale bara: $A, B, E, F, I, J, 20 \mu \mathrm{m} ; C, D, G, H, K, L, 50 \mu \mathrm{m}$.
$T l \times 3^{-1-}$ mice revealed that $T l \times 3$ was required for Vacht expression at E18.5 but not at E12.5, although it was required for the expression of cholinergic peptides VIP and SOM at both stages. Furthermore, we found that $T l \times 3$ controlled the expression of Ret at a high level, and Ret expression was required for the expression of Vip and Sst mRNAs at the late prenatal stage. These results shed light on the molecular mechanisms underlying differentiation of cholinergic neurons in the embryonic sympathetic nervous system.

\section{Transcriptional control of neurotransmitter phenotypes in sympathetic ganglia}

Diverse sympathetic neurons are derived from the multipotent neural crest progenitors (Goridis and Rohrer, 2002). For the postnatal acquisition of cholinergic phenotype in sympathetic neurons, it is well known that target-derived signals are responsible for the switch of the noradrenergic phenotype to the cholinergic fate (Landis, 1990; Asmus et al., 2000). However, cholinergic phenotype was observed in a small population of embryonic sympathetic neurons (Ernsberger et al., 1997; Schäfer et al., 1997; Schütz et al., 1998). The development of these embryonic cholinergic neurons is still poorly understood. It has been reported that transcription factor Phox $2 b$ was required for the early cholinergic differentiation at E11.5, because cholinergic markers Chat and Vacht were absent in the sympathetic ganglia of Phox $2 b$ knock-out mice (Huber and Ernsberger, 2006). Because the expression of noradrenergic markers and generic neuronal 

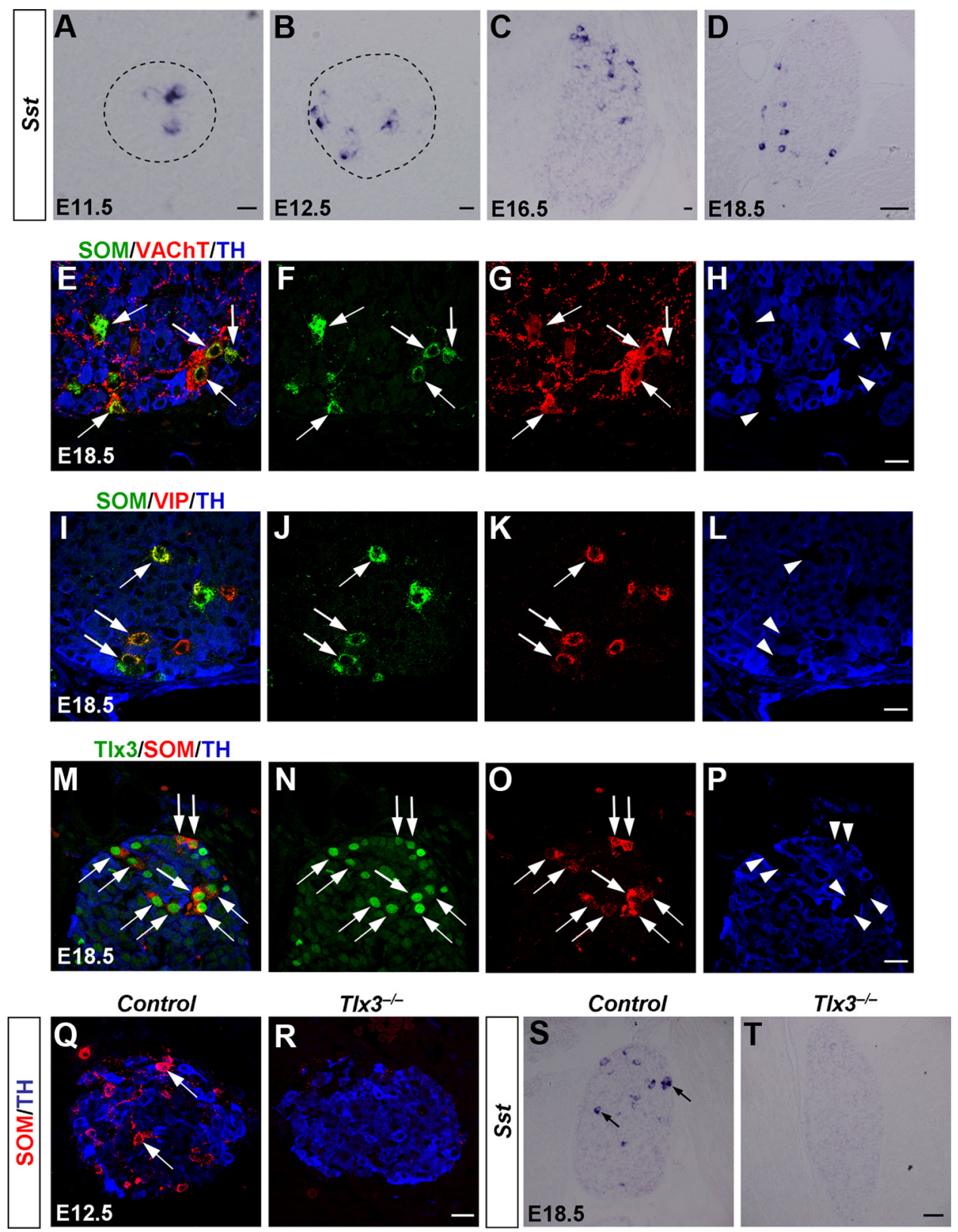

Figure 6. SOM or Sst was expressed in cholinergic sympathetic neurons and their expression was abolished in $T / x 3^{-/-}$mice. $A-D$, In situ hybridization was performed on sections of primary sympathetic chain at E11.5 (A), and stellate ganglia at E12.5 (B), E16.5( $)$, and E18.5 (D) with Sst as the probe. Strong signals were detected in a small subset of neurons in the embryonic sympathetic ganglia. $\boldsymbol{E}-\boldsymbol{H}$, Triple immunostaining of SOM, VAChT, and TH was performed on sections of stellate ganglia from wild-type mice at E18.5. The majority of SOM ${ }^{+} \mathrm{cell} \mathrm{Swere} \mathrm{VAChT}^{+} / \mathrm{TH}^{-}{ }^{-}$cholinergic neurons (arrows and arrowheads). $I-L$, Triple immunostaining of SOM, VIP, and TH was performed on sections of stellate ganglia from wild-type mice at E18.5. A large portion of VIP ${ }^{+} / \mathrm{TH}^{-}{ }^{-}$cells expressed SOM (arrows and arrowheads). $\boldsymbol{M}-\boldsymbol{P}$, Triple immunostaining of TIX3, SOM, and TH was performed on sections of stellate ganglia from wild-type mice at E18.5. Most SOM ${ }^{+} / \mathrm{TH}^{-}{ }^{-}$cells expressed TIX3 (arrows and arrowheads). Q- $\boldsymbol{Q}$, Expression of SOM or Sst in the stellate ganglia from $T / \times 3^{-1-}$ mice. Double-staining of SOM and TH was performed on sections of E12.5 stellate ganglia from control and $T / \times 3^{-1-}$ mice $(\boldsymbol{Q}, \boldsymbol{R})$. In situ hybridization was performed on sections of stellate ganglia from control and $T / \times 3^{-1-}$ mice at E18.5 (S, $\left.T\right)$. Note a complete loss of expression of SOM or Sst in T/x $3^{-1-}$ mice at both E12.5 and E18.5.Scale bars: E-R, $10 \mu \mathrm{m} ; A-C, 20 \mu \mathrm{m} ; D, S, T, 50 \mu \mathrm{m}$.

properties were impaired in sympathetic neurons of these Phox $2 b$ knock-out mice (Pattyn et al., 1999), it is possible that a general deficiency of neuronal differentiation or cell death could underlie the absence of cholinergic markers in these mice (Huber and Ernsberger, 2006). Furthermore, a recent study reported that ongoing Phox $2 b$ expression was not required for the maintenance of cholinergic differentiation during embryogenesis (Coppola et al., 2010). Ret is also required for the acquisition of cholinergic properties in embryonic sympathetic neurons (Burau et al., 2004). In the present study, we showed that transcription factor $T l \times 3$ controls the cholinergic neuronal development and is required for the expression of Ret at a high level (Figs. 4, 6, 7). Furthermore, we found that Ret controlled the expression of cholinergic peptide genes Vip and Sst in embryonic sympathetic neurons (Fig. $7 M-T)$. The fate of prenatal cholinergic neurons in stellate ganglia and potential targets they innervate remain unknown (Guidry and Landis, 1998; Anderson et al., 2006; Schütz et al., 2008; Apostolova and Dechant, 2009; Cane and Anderson, 2009). Further studies on fate mapping and neuronal projection are needed to clarify these issues. What roles $T l \times 3$ plays in controlling the postnatal emergence of cholinergic neurons remains unknown. Because Tlx3 knock-out mice die shortly after birth (Shi- 
rasawa et al., 2000), it also will be of interest to study whether $T l x 3$ is required for the acquisition of the postnatal cholinergic properties by analyzing the $T l \times 3$ conditional knock-out mice.

\section{Differential regulation of transmitter and peptide in cholinergic neurons}

The peptide VIP is expressed in the cholinergic neurons of newborn mice (Stanke et al., 2000). We showed here that the peptide SOM was expressed in embryonic cholinergic neurons as well (Fig. 6E-H). By analyzing the gene deletion mice, we found that the expression of Vip and Sst mRNAs required Tlx3 but not Ret at the early embryonic stage (E12.5) (Figs. 4E,F, $6 Q, R, 7 M, N, Q, R)$, suggesting that $T l x 3$ may be required for the initiation whereas Ret is only needed for the maintenance of VIP and SOM expression. On the other hand, Tlx3 and Ret are both required for Vacht expression at the late (E18.5 or newborn mice) but not early (E12.5 or E13) embryonic stage (Burau et al., 2004) (Fig. $4 A-D)$, suggesting these genes are both required for the maintenance but not the initiation of Vacht expression. Thus, cholinergic transmitter and the peptide phenotypes in the prenatal sympathetic ganglia are differentially regulated. Such differential regulation was also observed in the target-dependent acquisition of cholinergic properties as well. In chick sympathetic ganglia, the timing of Vip expression correlates with the innervation of peripheral targets by sympathetic fibers (Ernsberger et al., 1997). Interestingly, the expression of Vip but not Chat in these sympathetic ganglia depends on the cytokines signaling through heterodimeric gp130/LIFR $\beta$ receptors (Geissen et al., 1998; Duong et al., 2002). In contrast to that found in chick, gp130 signaling is essential for the postnatal target-dependent expression of both VIP and VAChT in sympathetic stellate ganglia of the mouse (Stanke et al., 2006). Two recent studies also reported differential dependence of the cholinergic loci Vacht and Chat vs Vip gene on Satb2 and p38 activities that are essential for cholinergic trans-differentiation of sympathetic neurons (Apostolova et al., 2010; Loy et al., 2011). Thus, differential regulation of transmitter and neuropeptide phenotypes may be a general phenomenon in both embryonic and postnatal development of cholinergic neurons.

\section{References}

Anderson CR, Bergner A, Murphy SM (2006) How many types of cholinergic sympathetic neuron are there in the rat stellate ganglion? Neuroscience 140:567-576. CrossRef Medline

Apostolova G, Dechant G (2009) Development of neurotransmitter phenotypes in sympathetic neurons. Auton Neurosci 151:30-38. CrossRef Medline

Apostolova G, Dorn R, Ka S, Hallböök F, Lundeberg J, Liser K, Hakim V, Brodski $I-L, O, P, S, T, 50 \mu \mathrm{m}$.
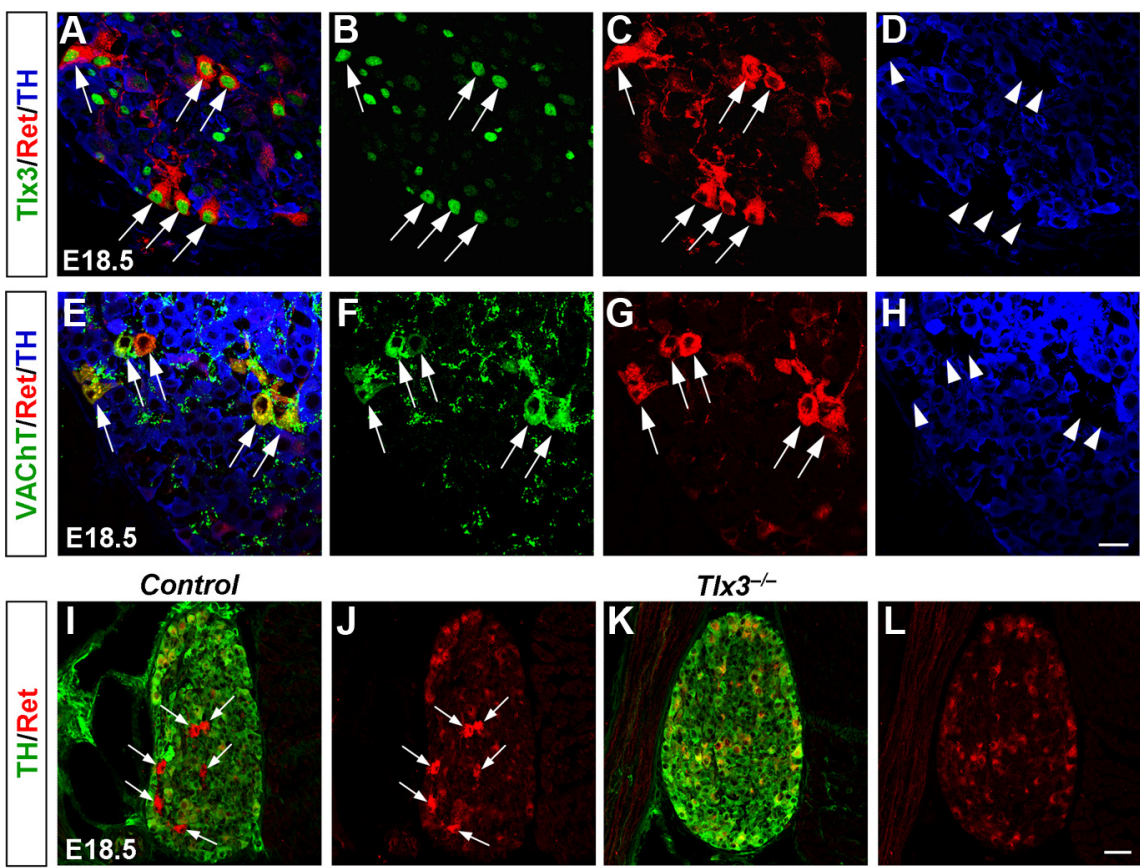

$T / \times 3^{-1}$
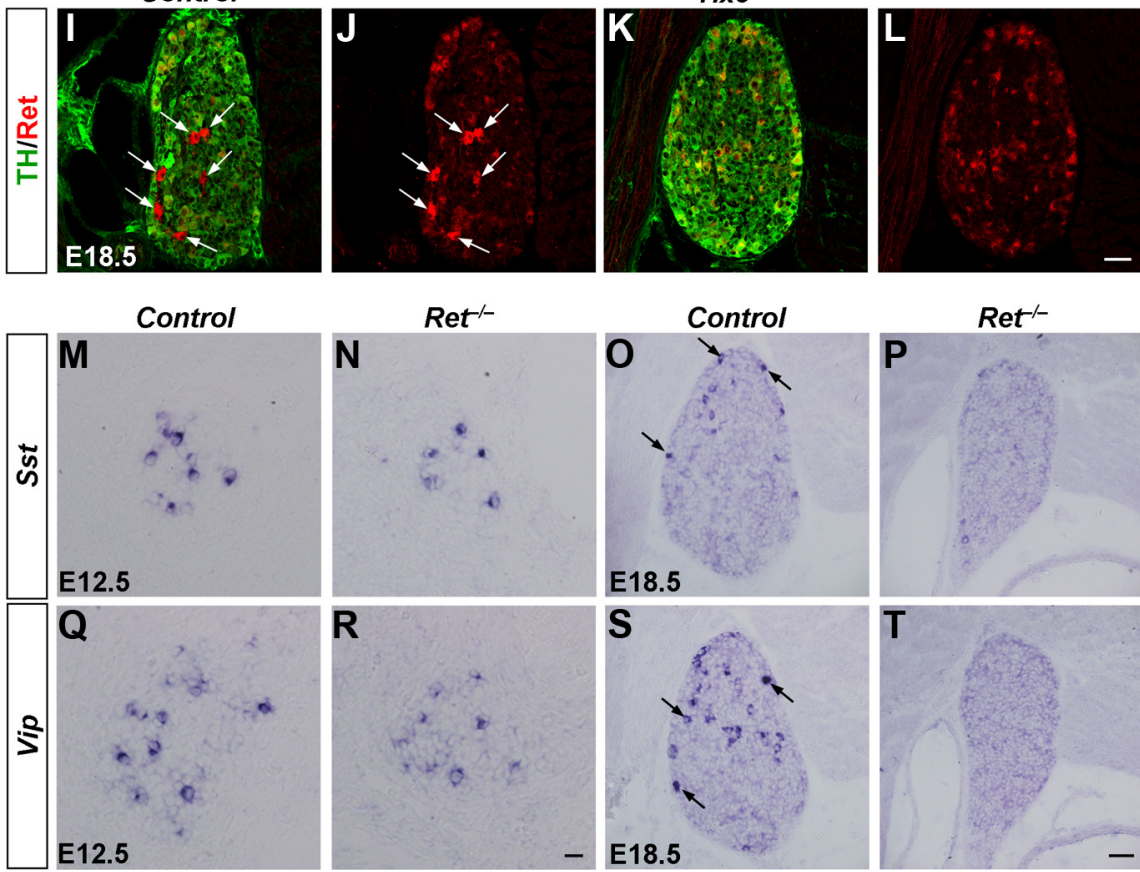

Figure 7. T/x3 and Ret in regulating the acquisition of cholinergic properties. $A-D$, Triple immunostaining of TIx3, Ret, and TH was performed on sections of stellate ganglia from wild-type mice at E18.5. $\boldsymbol{E}-\boldsymbol{H}$, Triple immunostaining of VAChT, Ret, and TH was performed on sections of stellate ganglia from wild-type mice at E18.5. I-L, Double-staining of Ret and TH was performed on sections of stellate ganglia from control and $T / \times 3^{-1-}$ mice at E18.5 $(I, K)$. The expression of Ret in the from control and Ret $^{-1-}$ mice at E12.5 and E18.5 with Sst $(\boldsymbol{M}-\boldsymbol{P})$, and $\operatorname{Vip}(\mathbf{Q}-\boldsymbol{T})$ as the probes. Note that the expression of Sst and Vip was detectable in Ret ${ }^{-1-}$ mice at E12.5, but abolished at E18.5. Scale bars: $\boldsymbol{A}-\boldsymbol{H}, 10 \mu \mathrm{m} ; \boldsymbol{M}, \mathbf{N}, \mathbf{Q}, \boldsymbol{R}, 20 \mu \mathrm{m}$;

C, Michaelidis TM, Dechant G (2007) Neurotransmitter phenotype-specific expression changes in developing sympathetic neurons. Mol Cell Neurosci 35:397-408. CrossRef Medline

Apostolova G, Loy B, Dorn R, Dechant G (2010) The sympathetic neurotransmitter switch depends on the nuclear matrix protein Satb2. J Neurosci 30:16356-16364. CrossRef Medline

Asmus SE, Parsons S, Landis SC (2000) Developmental changes in the transmitter properties of sympathetic neurons that innervate the periosteum. J Neurosci 20:1495-1504. Medline

Burau K, Stenull I, Huber K, Misawa H, Berse B, Unsicker K, Ernsberger U (2004) c-ret regulates cholinergic properties in mouse sympathetic neurons: evidence from mutant mice. Eur J Neurosci 20:353-362. CrossRef Medline

Cane KN, Anderson CR (2009) Generating diversity: mechanisms regulating the differentiation of autonomic neuron phenotypes. Auton Neurosci 151:17-29. CrossRef Medline

Cannon WB (1939) The wisdom of the body. New York: W. W. Norton. 
Cheng L, Arata A, Mizuguchi R, Qian Y, Karunaratne A, Gray PA, Arata S, Shirasawa S, Bouchard M, Luo P, Chen CL, Busslinger M, Goulding M, Onimaru H, Ma Q (2004) Tlx3 and Tlx1 are post-mitotic selector genes determining glutamatergic over GABAergic cell fates. Nat Neurosci 7:510-517. CrossRef Medline

Cheng L, Samad OA, Xu Y, Mizuguchi R, Luo P, Shirasawa S, Goulding M, Ma Q (2005) Lbx1 and Tlx3 are opposing switches in determining GABAergic versus glutamatergic transmitter phenotypes. Nat Neurosci 8:1510-1515. CrossRef Medline

Coppola E, d'Autréaux F, Rijli FM, Brunet JF (2010) Ongoing roles of Phox2 homeodomain transcription factors during neuronal differentiation. Development 137:4211-4220. CrossRef Medline

Duong CV, Geissen M, Rohrer H (2002) The developmental expression of vasoactive intestinal peptide (VIP) in cholinergic sympathetic neurons depends on cytokines signaling through LIFRbeta-containing receptors. Development 129:1387-1396. Medline

Elfvin LG, Lindh B, Hökfelt T (1993) The chemical neuroanatomy of sympathetic ganglia. Annu Rev Neurosci 16:471-507. CrossRef Medline

Ernsberger U (2001) The development of postganglionic sympathetic neurons: coordinating neuronal differentiation and diversification. Auton Neurosci 94:1-13. CrossRef Medline

Ernsberger U, Rohrer H (1999) Development of the cholinergic neurotransmitter phenotype in postganglionic sympathetic neurons. Cell Tissue Res 297:339-361. CrossRef Medline

Ernsberger U, Patzke H, Rohrer H (1997) The developmental expression of choline acetyltransferase (ChAT) and the neuropeptide VIP in chick sympathetic neurons: evidence for different regulatory events in cholinergic differentiation. Mech Dev 68:115-126. CrossRef Medline

Francis NJ, Landis SC (1999) Cellular and molecular determinants of sympathetic neuron development. Annu Rev Neurosci 22:541-566. CrossRef Medline

Furlan A, Lübke M, Adameyko I, Lallemend F, Ernfors P (2013) The transcription factor $\mathrm{Hmxl}$ and growth factor receptor activities control sympathetic neurons diversification. EMBO J 32:1613-1625. CrossRef Medline

Geissen M, Heller S, Pennica D, Ernsberger U, Rohrer H (1998) The specification of sympathetic neurotransmitter phenotype depends on gp130 cytokine receptor signaling. Development 125:4791-4801. Medline

Gibbins IL (1995) Chemical neuroanatomy of sympathetic ganglia. In: Autonomic ganglia (McLachlan EM, ed), pp 73-122. Luxembourg: Harwood Academic.

Goridis C, Rohrer H (2002) Specification of catecholaminergic and serotonergic neurons. Nat Rev Neurosci 3:531-541. CrossRef Medline

Guidry G, Landis SC (1998) Target-dependent development of the vesicular acetylcholine transporter in rodent sweat gland innervation. Dev Biol 199:175-184. CrossRef Medline

Guo Z, Zhao C, Huang M, Huang T, Fan M, Xie Z, Chen Y, Zhao X, Xia G, Geng J, Cheng L (2012) Tlx1/3 and Ptfla control the expression of distinct sets of transmitter and peptide receptor genes in the developing dorsal spinal cord. J Neurosci 32:8509-8520. CrossRef Medline

Howard MJ (2005) Mechanisms and perspectives on differentiation of autonomic neurons. Dev Biol 277:271-286. CrossRef Medline

Hu J, Huang T, Li T, Guo Z, Cheng L (2012) c-maf is required for the development of dorsal horn laminae III/IV neurons and mechanoreceptive DRG axon projections. J Neurosci 32:5362-5373. CrossRef Medline

Huang M, Huang T, Xiang Y, Xie Z, Chen Y, Yan R, Xu J, Cheng L (2008) Ptf1a, Lbx1 and Pax 2 coordinate glycinergic and peptidergic transmitter phenotypes in dorsal spinal inhibitory neurons. Dev Biol 322:394405. CrossRef Medline

Huang T, Liu Y, Huang M, Zhao X, Cheng L (2010) Wnt1-cre-mediated conditional loss of dicer results in malformation of the midbrain and cerebellum and failure of neural crest and dopaminergic differentiation in mice. J Mol Cell Biol 2:152-163. CrossRef Medline

Huber K (2006) The sympathoadrenal cell lineage: specification, diversification, and new perspectives. Dev Biol 298:335-343. CrossRef Medline

Huber K, Ernsberger U (2006) Cholinergic differentiation occurs early in mouse sympathetic neurons and requires Phox2b. Gene Expr 13:133139. CrossRef Medline

Jänig W, McLachlan EM (1992) Characteristics of function-specific path- ways in the sympathetic nervous system. Trends Neurosci 15:475-481. CrossRef Medline

Landis SC (1990) Target regulation of neurotransmitter phenotype. Trends Neurosci 13:344-350. CrossRef Medline

Landis SC, Fredieu JR (1986) Coexistence of calcitonin gene-related peptide and vasoactive intestinal peptide in cholinergic sympathetic innervation of rat sweat glands. Brain Res 377:177-181. CrossRef Medline

Le Douarin NM, Kalcheim C (1999) The neural crest. Cambridge, UK: Cambridge UP.

Loy B, Apostolova G, Dorn R, McGuire VA, Arthur JS, Dechant G (2011) p38alpha and p38beta mitogen-activated protein kinases determine cholinergic transdifferentiation of sympathetic neurons. J Neurosci 31:12059-12067. CrossRef Medline

Masliukov PM, Timmermans JP (2004) Immunocytochemical properties of stellate ganglion neurons during early postnatal development. Histochem Cell Biol 122:201-209. CrossRef Medline

Pattyn A, Morin X, Cremer H, Goridis C, Brunet JF (1997) Expression and interactions of the two closely related homeobox genes Phox $2 \mathrm{a}$ and Phox $2 \mathrm{~b}$ during neurogenesis. Development 124:4065-4075. Medline

Pattyn A, Morin X, Cremer H, Goridis C, Brunet JF (1999) The homeobox gene Phox $2 \mathrm{~b}$ is essential for the development of autonomic neural crest derivatives. Nature 399:366-370. CrossRef Medline

Qian Y, Shirasawa S, Chen CL, Cheng L, Ma Q (2002) Proper development of relay somatic sensory neurons and D2/D4 interneurons requires homeobox genes Rnx/Tlx-3 and Tlx-1. Genes Dev 16:1220-1233. CrossRef Medline

Rohrer H (2011) Transcriptional control of differentiation and neurogenesis in autonomic ganglia. Eur J Neurosci 34:1563-1573. CrossRef Medline

Schäfer MK, Schütz B, Weihe E, Eiden LE (1997) Target-independent cholinergic differentiation in the rat sympathetic nervous system. Proc Natl Acad Sci U S A 94:4149-4154. CrossRef Medline

Schmidt M, Lin S, Pape M, Ernsberger U, Stanke M, Kobayashi K, Howard MJ, Rohrer H (2009) The bHLH transcription factor Hand2 is essential for the maintenance of noradrenergic properties in differentiated sympathetic neurons. Dev Biol 329:191-200. CrossRef Medline

Schuchardt A, D'Agati V, Larsson-Blomberg L, Costantini F, Pachnis V (1994) Defects in the kidney and enteric nervous system of mice lacking the tyrosine kinase receptor Ret. Nature 367:380-383. CrossRef Medline

Schütz B, Schäfer MK, Eiden LE, Weihe E (1998) Vesicular amine transporter expression and isoform selection in developing brain, peripheral nervous system and gut. Brain Res Dev Brain Res 106:181-204. CrossRef Medline

Schütz B, von Engelhardt J, Gördes M, Schäfer MK, Eiden LE, Monyer H, Weihe E (2008) Sweat gland innervation is pioneered by sympathetic neurons expressing a cholinergic/noradrenergic cophenotype in the mouse. Neuroscience 156:310-318. CrossRef Medline

Shirasawa S, Arata A, Onimaru H, Roth KA, Brown GA, Horning S, Arata S, Okumura K, Sasazuki T, Korsmeyer SJ (2000) Rnx deficiency results in congenital central hypoventilation. Nat Genet 24:287-290. CrossRef Medline

Stanke M, Geissen M, Götz R, Ernsberger U, Rohrer H (2000) The early expression of VAChT and VIP in mouse sympathetic ganglia is not induced by cytokines acting through LIFRbeta or CNTFRalpha. Mech Dev 91:91-96. CrossRef Medline

Stanke M, Duong CV, Pape M, Geissen M, Burbach G, Deller T, Gascan H, Otto C, Parlato R, Schütz G, Rohrer H (2006) Target-dependent specification of the neurotransmitter phenotype: cholinergic differentiation of sympathetic neurons is mediated in vivo by gp 130 signaling. Development 133:141-150. CrossRef Medline

Tsarovina K, Reiff T, Stubbusch J, Kurek D, Grosveld FG, Parlato R, Schütz G, Rohrer H (2010) The Gata3 transcription factor is required for the survival of embryonic and adult sympathetic neurons. J Neurosci 30:10833-10843. CrossRef Medline

Xu Y, Lopes C, Qian Y, Liu Y, Cheng L, Goulding M, Turner EE, Lima D, Ma Q (2008) Tlx1 and Tlx3 coordinate specification of dorsal horn painmodulatory peptidergic neurons. J Neurosci 28:4037-4046. CrossRef Medline 